\title{
Effects of mercury and nickel impurities on optical properties of copper sulfide (CuS) thin films deposited by chemical bath technique.
}

\author{
J. C. Osuwa ${ }^{1}$ and E. C Mgbaja ${ }^{2}$ \\ Department of Physics, Michael Okpara University of Agriculture, Umudike, PMB 7267, Abia State, Nigeria
}

\begin{abstract}
Thin films of copper sulfide (CuS) with varying concentrations of mercury $(\mathrm{Hg})$ and nickel $(\mathrm{Ni})$ impurities (0.01M-0.03M) were grown on glass substrates at room temperature (300K) using chemical bath deposition technique. Spectral transmittance and reflectance of the thin films were measured with a spectrophotometer in the UV-Vis-IR region of the electromagnetic spectrum. The effects of the impurities on other optical spectra obtained theoretically were quantitatively evaluated from the spectrophotometer data. The energy band gap increased for all $\mathrm{Hg}$ impurity concentrations to a maximum of $3.25 \mathrm{eV}$ for $0.02 \mathrm{M} \mathrm{Hg}$ impurity as against $2.65 \mathrm{eV}$ for as grown $\mathrm{CuS}$ thin film, while the band gap decreased for all Ni impurity concentrations to a minimum of $1.85 \mathrm{eV}$ for $\mathrm{O} .01 \mathrm{M} \mathrm{Ni}$ impurity. The absorbance increased with both $\mathrm{Hg}$ and Ni impurity concentrations while the transmittance decreased with Ni impurities and increased with $\mathrm{Hg}$ impurities. The results also show increase in absorption coefficient and decrease in reflectance for both $\mathrm{Hg}$ and Ni impurities with a maximum reflectance of $70 \%$ for as grown thin film down to $10 \%$ wlth 0.01 Ni impurity. Values for the refractive index reduced to 1.0 with $0.01 M$ of both impurities from a maximum of 2.4 for as grown CuS thin film. Also, results of the absorbance, transmittance and reflectance as presented here converged at $300 \mathrm{~nm}$ and diverged to $900 \mathrm{~nm}$ wavelength limit.
\end{abstract}

Keywords: $\mathrm{Hg}$ and Ni impurities, optical properties, impurity concentrations, copper sulfide.

\section{Introduction}

Continued interest in chalcogenide binary compounds is due to their electronic and optical applications [1]. Copper sulfide belongs to I-VI compound semiconductor metals. It is a p-type semiconducting material. Chalcogenide thin films of copper sulfide have received particular attention since the discovery of the $\mathrm{CdS} / \mathrm{CuS}$ hetrojucntion solar cell in 1954 [2]. The range of applications of CuS thin films include laminated glazing, photo-thermal conversion, electro-conductive electrode, microwave shielding and solar control coatings [3-5]. It is also used in photo-detectors and photovoltaic applications.

In this work, the effects of impurity ions of mercury and nickel on the optical properties of $\mathrm{CuS}$ thin films have been investigated in order to further broaden the range of applications. The thin films were deposited using the versatile chemical bath deposition method which combines simplicity and low cost with potentials for large scale production. [6-10].

\section{Experimental Details:}

Analytical grade reagents used for the $\mathrm{CuS}$ thin film deposition include copper sulphate $\left(\mathrm{CuSO}_{4}\right)$ as the precursor for copper ions, tri ethanol amine (TEA) as a complexing agent, thiourea $\left(\mathrm{CS}\left(\mathrm{NH}_{2}\right)_{2}\right)$ as the precursor for sulfur ions and ammonia as the $\mathrm{pH}$ adjuster. Glass substrates were degreased with hydrochloric acid $(\mathrm{Hcl})$ for 48 hours, washed in cold water with detergent, rinsed with distilled water and dried in air for some minutes.

$7.5 \mathrm{ml}$ of $0.755 \mathrm{M}$ of already prepared tri ethanol amine was measured out with clinical syringe and poured into $100 \mathrm{ml}$ beaker that already contained $15 \mathrm{ml}$ of $0.1 \mathrm{M} \mathrm{CuSO}_{4}$ solution. The mixture was stirred, after which $30 \mathrm{ml}$ of thiourea solution was measured and added to the beaker with constant stirring. Finally, $4.5 \mathrm{ml}$ of ammonia $\left(\mathrm{NH}_{3}\right)$ was added to the mixture.

Cleansed glass substrates were then inserted vertically into the reaction bath with the help of a synthetic foam/holder, which also partly covered the top of the beaker containing the bath. The bath was left undisturbed for 3 to 5 hours at a constant room temperature of $300 \mathrm{~K}$. This was followed with varying concentrations of mercury chloride and nickel chloride, the sources of nickel and mercury impurity ions, which were mixed separately with copper sulphate in different beakers and stirred thoroughly. Other reagents were orderly added as in the case of copper sulfide deposition. The mixtures were again thoroughly stirred and cleansed glass substrates were inserted and left undisturbed for hours for the deposition of the doped thin films.

After deposition, the substrates were taken out, rinsed in distilled water, dried in air and stored for analysis. 


\section{Results and Discussion}

The optical data for the doped and as grown copper sulfide thin films were measured with double beam UV-Vis spectrophotometer in the wavelength range of 300-900 nm. Figure 1 (a-d) show the absorbance and transmittance spectra of both as grown and doped copper sulfide thin films. In fig. 1(a), the introduction of mercury impurities increased the absorbance from the lowest value of about 0.1 for as grown $\mathrm{CuS}$ thin film to 0.5 for $0.01 \mathrm{M} \mathrm{Hg}$ impurity at $900 \mathrm{~nm}$ wavelength. Figure 1(c) also shows increase in transmittance by mercury impurities from $20 \%$ for as grown film to about $32 \%$ for $0.02 \mathrm{M} \mathrm{Hg}$ impurity concentration. In fig. 1(b), the presence of nickel impurities also increased the absorbance from 0.1 for as grown thin film to 0.8 for $0.01 \mathrm{M} \mathrm{Ni}$ impurity at $900 \mathrm{~nm}$ wavelength, while fig. 1(d) shows decrease in transmittance with Ni impurities from $20 \%$ for as grown thin film to about $5 \%$ for $0.01 \mathrm{M}$ impurity concentration at $900 \mathrm{~nm}$ wavelength. We also note the convergence of all values of the absorbance, transmittance and reflectance at $300 \mathrm{~nm}$ wavelength.

Figure 2.(a-d) show the reflectance and absorption coefficients of the thin films. Figure 2 (a) and (b) show decrease in reflectance for both $\mathrm{Hg}$ and $\mathrm{Ni}$ impurity ions from a maximum of $70 \%$ for as grown film to as low as $10 \%$ for $0.01 \mathrm{M}$ Ni impurity concentration. The values of the absorption

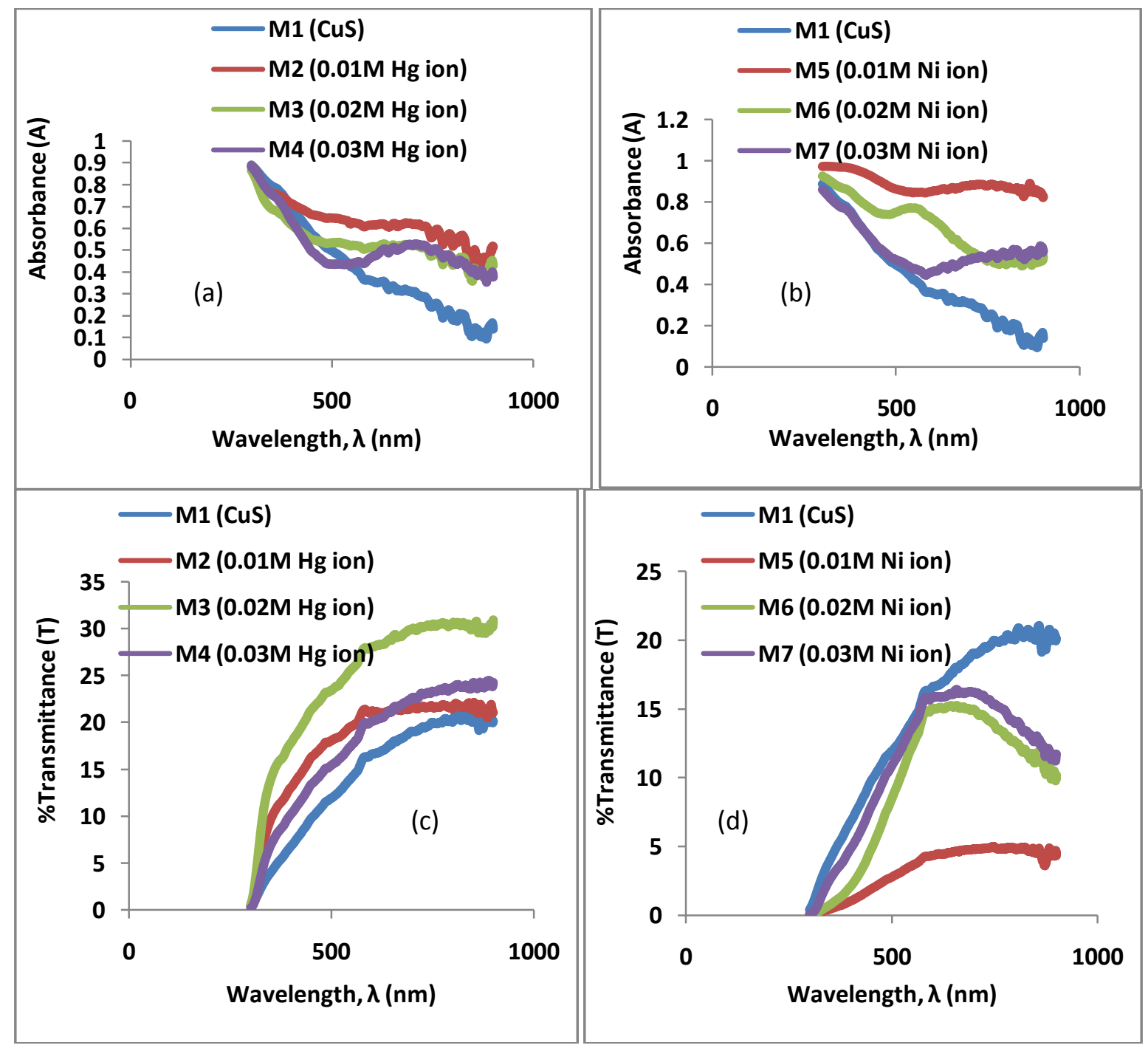

Fig.1: Absorbance and Transmittance spectra as functions of wavelength for $\mathrm{CuS}$ thin films for varying concentrations of impurities (a) and (c) mercury impurities, (b) and (d) nickel impurities.

coefficients in fig.2 (c) and (d) increased for all concentrations of impurity ions of mercury and nickel.

The direct energy band gap obtained in fig.3 (a) shows increase in values with mercury impurities from $2.6 \mathrm{eV}$ for as grown thin film to a maximum of $3.25 \mathrm{eV}$ for $0.02 \mathrm{M} \mathrm{Hg}$ impurity, while fig. 3(b) for nickel impurities shows decrease in the values of the band gap down to $1.85 \mathrm{eV}$ for $0.01 \mathrm{M}$ of Ni impurity ion. Values for the extinction coefficient and refractive index are shown in fig. 4 (a-d). The extinction coefficient increased 
Effects of mercury and nickel impurities on optical properties of copper sulfide (CuS) thin films

for both impurity concentrations as shown in fig.4 (a) and (b) while the refractive index shown in fig.4 (c) and (d) decreased for both impurity concentrations to a minimum of 1.0 from a maximum of 2.5 for as grown $\mathrm{CuS}$ thin film.
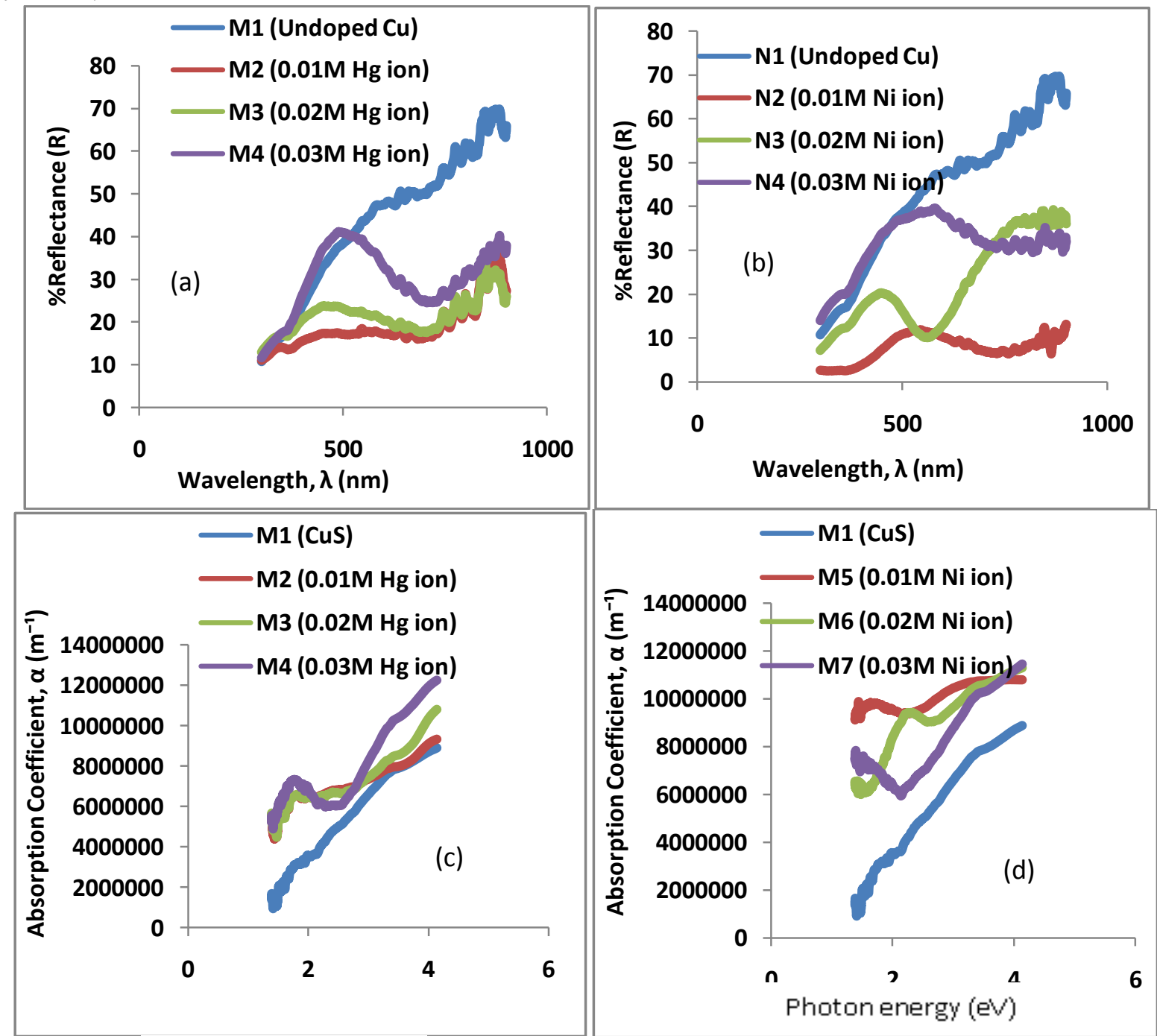

Fig. 2: Reflec films for vary

Photon energy $(\mathrm{eV}) \quad$ icient as functions of wavelength and energy respectively for CuS thin ities (a) and (c) mercury impurities, (b) and (d) nickel impurities.

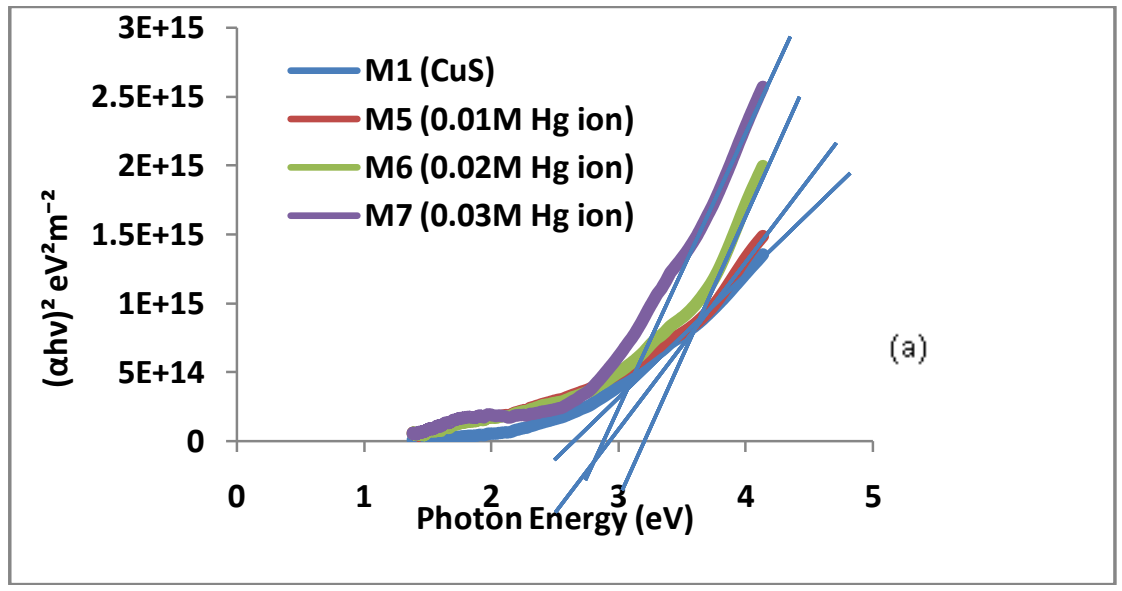




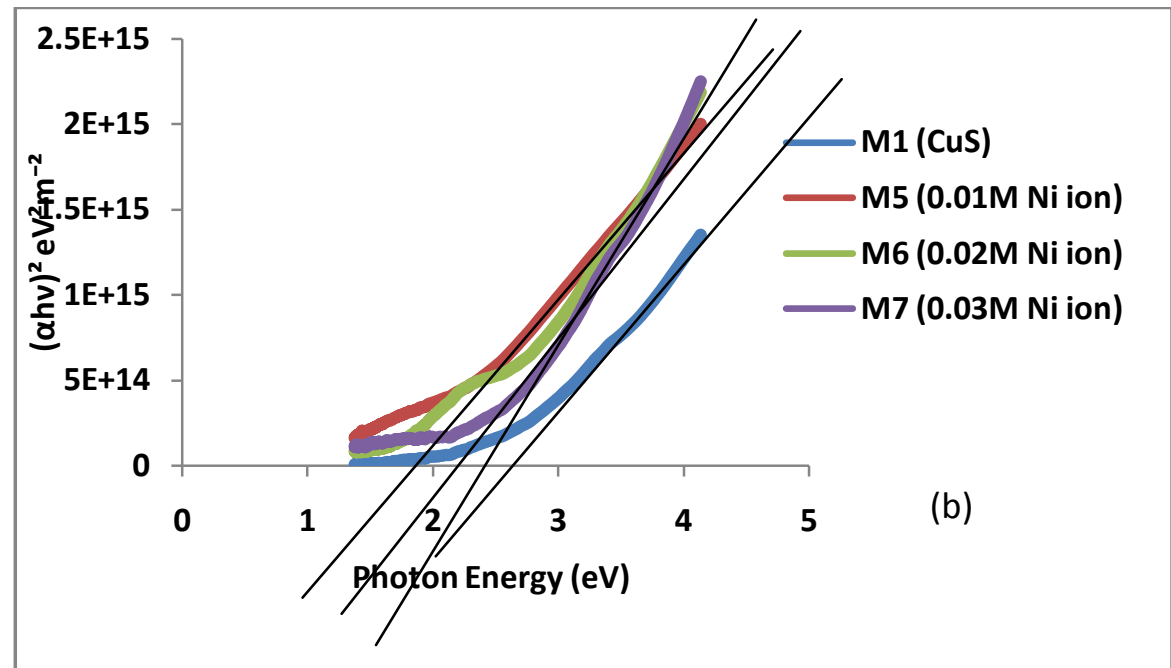

Fig. 3: Plot of $(\alpha h v)^{2}$ as a function of photon energy for CuS thin films for varying concentrations of impurities (a) mercury impurities and (b) nickel impurities.
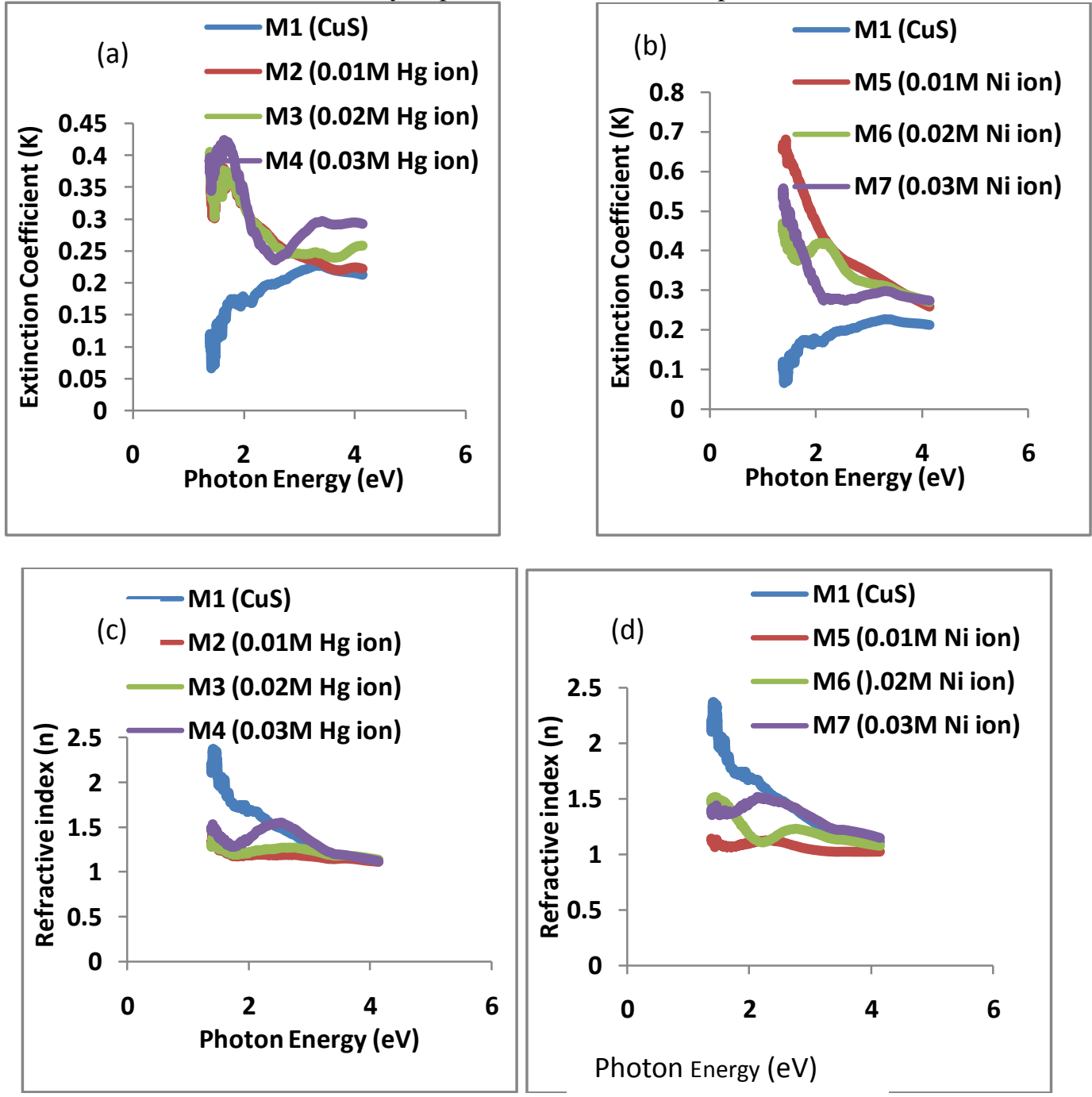

Fig.4: Extinction coefficient and refractive index for thin CuS tilms for varying concentrations of impurities (a) and (c) mercury impurities, (b) and (d) nickel impurities.

\section{Conclusion}

The effects of mercury and nickel impurities on the optical properties of copper sulfide thin films have been successfully investigated. Very substantial reductions and enhancements in the values of the transmittance, 
reflectance, absorbance, refractive index and other optical spectra are obtained with the introduction of the impurity ions. Remarkable among them is the increase in the energy band gap from $2.65 \mathrm{eV}$ to $3.25 \mathrm{eV}$ by 0.02 molar concentration of mercury ions and the decrease in band gap to $1.85 \mathrm{eV}$ from $2.65 \mathrm{eV}$ by 0.01 molar concentration of nickel ions. The lowering of reflectance from $70 \%$ to $10 \%$ by 0.01 nickel impurity and the reduction of refractive index from a maximum of 2.5 for un-doped copper sulfide thin film to 1.0 by $0.01 \mathrm{M}$ of both mercury and nickel impurity ions are also remarkable. Other interesting effects are reported in this paper.

Thus, the introduction of mercury and nickel impurities into copper sulfide thin film production greatly widens the scope of applications of the nano-material.

\section{References}

[1] Osuwa J. C, Oriaku I.C and Mgbaja E. C, (2010) Synthesis and Optical Parameters of Pb15Cd45S40 Layered Coating Chalcogenide Letters 7 (12) 679-684

[2] Pathan H.M, Lokhande C. D, (2004) Deposition of metal chalcogenide thin films by successive ionic layer adsorption and reaction (SILAR) method Bull. Mater. Sci. Vol. 27 No. 2 pp. 85-111

[3] Grozdanov I and Najdoski M (1995) Optical and Electrical properties of copper sulphide films of variable composition. J. Solid State Chem. 114469

[4] Suarez R and Nair P. K (1996) Co-Deposition of PbS-CuS thin films by chemical Technique. J. Solid State Chem. 123296

[5] Nascu C, Pop I, Ionescu V, Indrea E and Bratu I (1997) Spray pyrolysis of Cu thin films. Mater. Lett. 3273

[6] Popa A. M, Lisca V. S, Bada M, Pentia E and Bolita T (2000) Crystalline size effect In PbS thin films grown on glass substrates by chemical bath deposition. J. of Optoelectronics and Advanced Materials. Vol 8. No. 1

[7] Ugwu E. I (2006) Optical properties of Iron halide (FCl2) thin film deposited by using solution growth technique (SGT) Pacific Journal of Science and Technology 7 (2) 97-102

[8] Ottih I. E and Ekpunobi A.J (2010) X-ray and optical characterization of chemical bath deposited cadmium Nickel Sulphide CdNS thn films. Journal of Basic Physical Research Vol.I p 17-22

[9] Gosh P.K, Miltra M. K andChattopadhyay K. K (2005) ZnS nanobelts grown in a polymer matrix by chemical bath deposition. Nanotechnology 16, '07-112

[10] Ezema F. I, Ekwealor A. B. C and Osuji R.U (2006) Effect of thermal annealing on the band gap and optical properties of chemi cal bath deposited ZnSc thin film. Turkish Journal of Phsics 30, 157-163 